Proc. of the X Int. Conf. - Ion Implantation and other Applications of Ions and Electrons, Kazimierz Dolny 2014

\title{
Channeling Study of Co and Mn Implanted and Thermally Annealed Wide Band-Gap Semiconducting Compounds
}

\author{
R. Ratajczak ${ }^{a, *}$, Z. Werner ${ }^{a}$, M. Barlak $^{a}$, C. Pochrybniak $^{a}$, A. Stonert $^{a}$ \\ AND Q. ZHAO ${ }^{b}$ \\ ${ }^{a}$ National Centre for Nuclear Research, A. Sołtana 7, 05-400 Otwock, Poland \\ ${ }^{b}$ Instituut voor Kern-en Stralingsfysica, KU Leuven, 3001 Leuven, Belgium
}

\begin{abstract}
The defect build-up, structure recovery and lattice location of transition metals in ion bombarded and thermally annealed $\mathrm{ZnO}$ and $\mathrm{GaN}$ single crystals were studied by channeled Rutherford backscattering spectrometry and channeled particle-induced X-ray emission measurements using $1.57 \mathrm{MeV}{ }^{4} \mathrm{He}$ ions. Ion implantation to a fluence of $1.2 \times 10^{16}$ ions $/ \mathrm{cm}^{2}$ was performed using $120 \mathrm{keV}$ Co and $120 \mathrm{keV} \mathrm{Mn} \mathrm{ions.} \mathrm{Thermal} \mathrm{annealing} \mathrm{was} \mathrm{performed}$ at $800^{\circ} \mathrm{C}$ in argon flow. Damage distributions were determined using the Monte Carlo McChasy simulation code. The simulations of channeled Rutherford backscattering spectra reveal that the ion implantation leads to formation of two types of defect structures in $\mathrm{ZnO}$ and $\mathrm{GaN}$ such as point and extended defects, such as dislocations. The concentrations of both types of defects are at a comparable level in both structures and for both implanted ions. Differences between both implantations appear after thermal annealing where the Mn-doped $\mathrm{ZnO}$ reveals much better transition metals substitution and recovery effect.
\end{abstract}

DOI: 10.12693 /APhysPolA.128.845

PACS: 61.43.-j, 61.72.--y, 81.05.-t, 82.80.--d, 85.40.-e

\section{Introduction}

The goal of the present search for spintronic materials is to develop a material with properties necessary for a possibility of mutual interaction of electronic and magnetic systems of the material (semiconducting and ferromagnetic properties) at room temperature for possible applications in practical devices [1]. The semiconducting compounds such as $\mathrm{GaN}$ and $\mathrm{ZnO}$ doped with transition metals (TM) are well-established candidates for meeting this goal [2-5]. Although many $\mathrm{GaN}$ and $\mathrm{ZnO}$ properties are similar to one another, the GaN manufacture is much more difficult and expensive than that of $\mathrm{ZnO}$, so $\mathrm{ZnO}$ is a very attractive material for several new applications and became a good competitor to GaN. Modification of semiconductor properties by ion implantation is a well-established technological process. For the structures based on semiconducting compounds it is used for electrical doping, compositional mixing of quantum wells and formation of isolation regions. During ion implantation, point defects and their complexes are produced and they usually affect optical and electrical properties of the semiconductors. It might be detrimental for potential application devices, therefore a recovery of crystal structures as a result of an annealing process is so important. Moreover, magnetic properties of the TM-doped semiconductor strongly depend on both the concentration of the dopant and its lattice location in the structure [6-10]. In this work we present the defect build-up, recovery and also the lattice location of TM atoms in

${ }^{*}$ corresponding author; e-mail: renata.ratajczak@fuw.edu.pl
$\mathrm{ZnO}$ (0001) single crystals and GaN (0001) epitaxial layers after $120 \mathrm{keV} \mathrm{Co-ions} \mathrm{and} 120 \mathrm{keV}$ Mn-ions implantation to a fluence of $1.2 \times 10^{16}$ ions $/ \mathrm{cm}^{2}$ in both cases and after thermal annealing. Thermal annealing was performed at $800^{\circ} \mathrm{C}$ in argon flow. There processes were monitored by the channeled Rutherford backscattering spectrometry (cRBS) and channeled particle-induced Xray emission (cPIXE) measurements [11-13].

\section{Experimental}

Commercial (0001) $\mathrm{ZnO}$ single crystals (Mateck) and (0001) GaN $5 \mu \mathrm{m}$ thick EPI layers on sapphire (ITME, Poland) were implanted with $120 \mathrm{keV}$ Co and $120 \mathrm{keV}$ Mn ions. After implantation, part of samples was annealed at $800^{\circ} \mathrm{C}$ for $1 \mathrm{~h}$ in an Ar flow furnace.

All samples were analyzed using the cRBS and cPIXE methods. Experiments were conducted using the NEC Pelletron Accelerator (5SHD-2 Pelletron) with the Cssputtering source at the Molecular Beam Laboratory (IMBL) of Katholieke Universiteit Leuven (Belgium). The beam of $\mathrm{He}^{+}$accelerated to an energy of $1.57 \mathrm{MeV}$ was collimated and introduced into the scattering chamber, where the samples were mounted on a 3 -axis goniometer. The backscattered ions were detected at an angle of $167^{\circ}$ to the incidence direction with a Si surface barrier detector with an active area of $50 \mathrm{~mm}^{2}$. The Xrays were detected using a cooled Ge detector in the same chamber.

Finally, the Monte Carlo simulation McChasy computer code [14] was used to fit the cRBS spectra. The recent version of this program allowed for an analysis of the channeling spectra yielding the distribution of point defect structures (simulated as randomly displaced atoms, 
RDA) and extended defects such as: clusters, dislocations, loops, stacking faults, etc. (referred to as bent channels, BC) [15].

\section{Results and discussion}

Figure 1a and b shows the random and (0001) aligned RBS spectra for $\mathrm{ZnO}$ (0001) single crystals and GaN (0001) epitaxial layers prior to and after $120 \mathrm{keV} \mathrm{Co}$ ion implantation to a fluence of $1.2 \times 10^{16}$ ions $/ \mathrm{cm}^{2}$ ions and also after the thermal annealing process. As can be seen, for both structures the spectra show incomplete amorphisation after ion implantation, and partial recovery after annealing of the $\mathrm{ZnO}$ structure. For GaN, postimplantation damage after thermal annealing remains unchanged. Moreover, for the GaN structures some additional surface damage after the thermal annealing process was observed. As follows from our experience [16], this is probably beginning of GaN surface layer decomposition under these thermal annealing conditions.

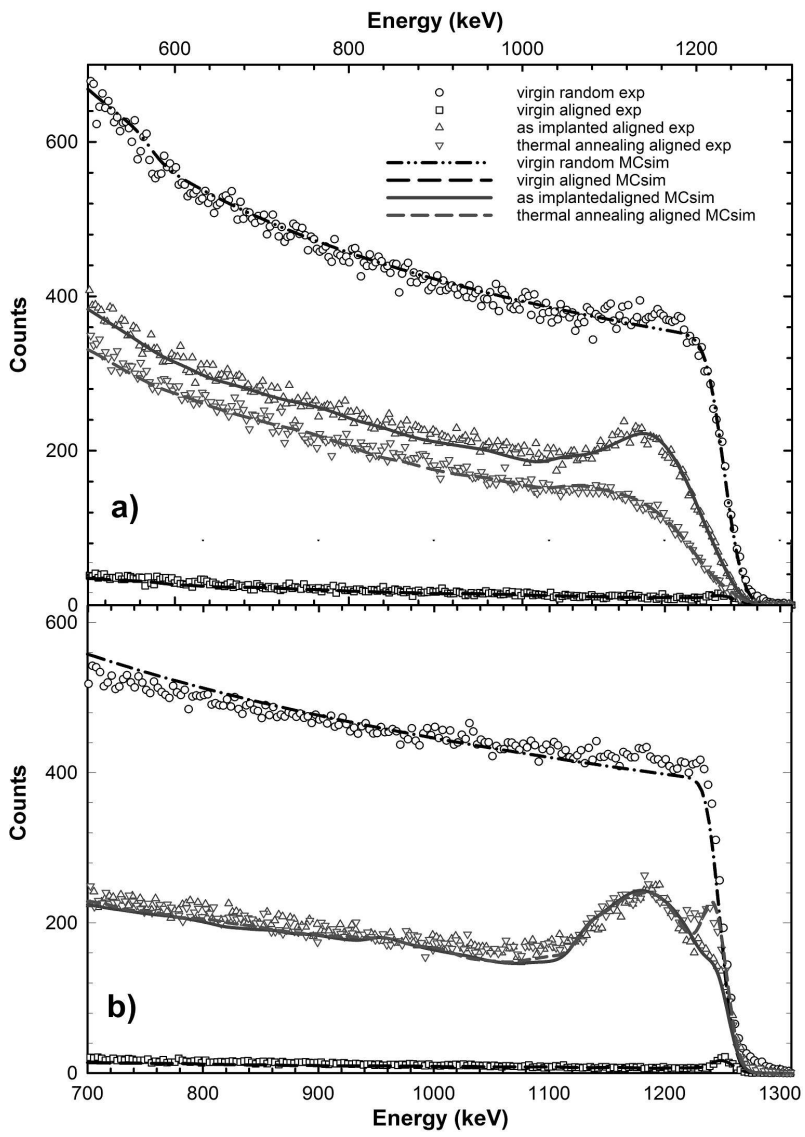

Fig. 1. The RBS random and aligned spectra obtained for (a) $\mathrm{ZnO}$ and (b) GaN before and after implantation with $120 \mathrm{keV}$ Co ions to a fluence $1.2 \times 10^{16}$ ions $/ \mathrm{cm}^{2}$ and after thermal annealing at $800{ }^{\circ} \mathrm{C}$. The solid lines show the results of $\mathrm{MC}$ simulations.

The solid line in Fig. 1a and b shows the results of $\mathrm{MC}$ simulations performed for the best fit to the damage peak located in the energy interval 1000-1250 keV assuming

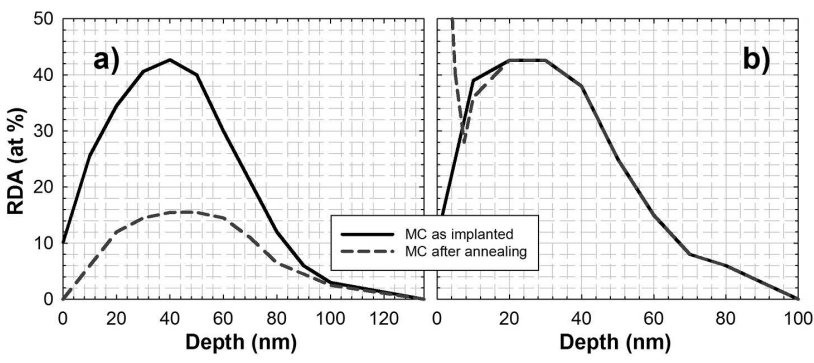

Fig. 2. Depth distribution of defects due to Co-ion bombardment of (a) $\mathrm{ZnO}$ and (b) GaN (results of MC simulations).

RDA and BC defects. The best fits were obtained for the RDA defect distributions extending to a depth of about $100 \mathrm{~nm}$ as shown in Fig. 2a and b and on the assumption of a constant level of extended defects (BC) over the whole implantation modified region. The McChasy calculations reveal that after thermal annealing of $\mathrm{ZnO}$, the concentrations of RDA defects change, but those of $\mathrm{BC}$ defects remain unchanged. This fact has an influence on magnetic properties of Co-doped $\mathrm{ZnO}$, as it was already reported [17].

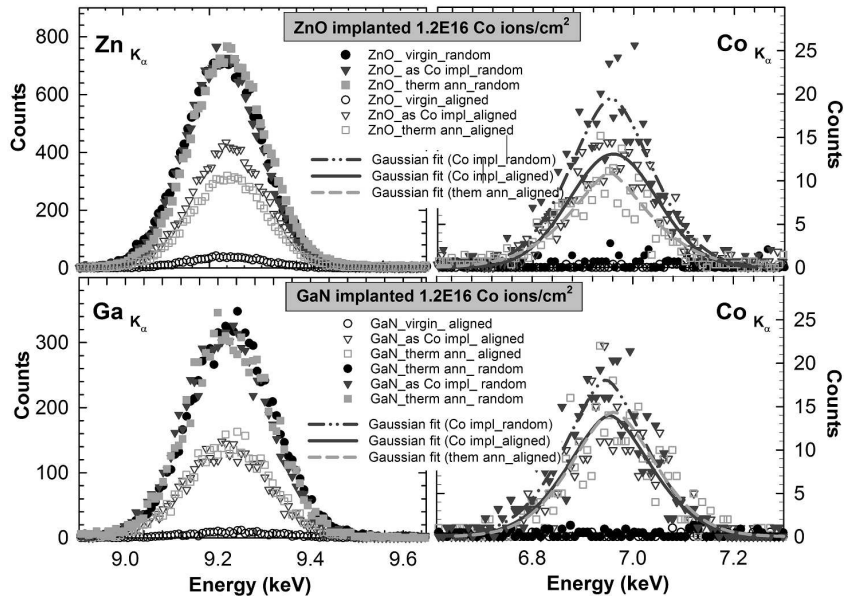

Fig. 3. The PIXE random and aligned spectra obtained for (a) $\mathrm{ZnO}$ and (b) GaN before and after implantation with $120 \mathrm{keV}$ Co ions to a fluence $1.2 \times 10^{16} / \mathrm{cm}^{2}$ and after thermal annealing at $800{ }^{\circ} \mathrm{C}$. The lines show Gaussian approximations of the spectra.

TABLE

Numerical results of the collected PIXE spectra.

\begin{tabular}{l|c|c|c|c}
\hline \hline & $\begin{array}{c}\text { Post-implantation } \\
\text { damage [\%] } \\
\text { (comparison aligned } \\
\text { as implanted } \\
\text { to random) }\end{array}$ & $\begin{array}{c}\text { Effect of thermal } \\
\text { annealing [\%] } \\
\text { (comparison aligned } \\
\text { thermal annealing } \\
\text { to random) }\end{array}$ \\
\cline { 2 - 5 } Zn or Ga & Co or $\mathrm{Mn}$ & Zn or Ga & Co or Mn \\
\hline ZnO impl Co & 56 & 70 & 43 & 52 \\
GaN impl Co & 43 & 86 & 46 & 90 \\
ZnO impl Mn & 56 & 56 & 29 & 32
\end{tabular}


From the viewpoint of magnetic properties, the question of Co lattice locations in the structure is of vital importance although it does not preclude ferromagnetism. The lattice location of TM was analyzed using the cPIXE technique. In principle, the cRBS method allows to specify the dopant location in the crystallographic structure. Unfortunately, in this specific case Mn and Co are lighter than $\mathrm{Zn}$ or $\mathrm{Ga}$ and in the RBS spectra the TM signal appears below Zn (Ga) signal detection threshold. The presence of the TM signal on a pedestal of $\mathrm{Zn}(\mathrm{Ga})$ signal prevents determination of TM location by this method. In the PIXE method the TM and $\mathrm{Zn}(\mathrm{Ga})$ signals are separated in energy. Figure 3 shows Zn, Ga, and Co peaks from the random and (0001) aligned cPIXE spectra obtained for $\mathrm{ZnO}(0001)$ single crystals and $\mathrm{GaN}$ (0001) epitaxial layers prior to and after $120 \mathrm{keV}$ Co ions bombardment to the $1.2 \times 10^{16}$ ions $/ \mathrm{cm}^{2}$ fluence and also after thermal annealing. An inspection of $\mathrm{Zn}$ and Ga signals reveals a compatibility of the information on postimplantation damage and structures recovery with that of the RBS spectra. The Co signal is rather weak, but its inspection shows that the implanted Co atoms are partially built into the $\mathrm{ZnO}$ structure after implantation, and this effect grows after thermal annealing. For GaN no Co-substitution was observed. The numerical results of the collected PIXE spectra are presented in the Table.

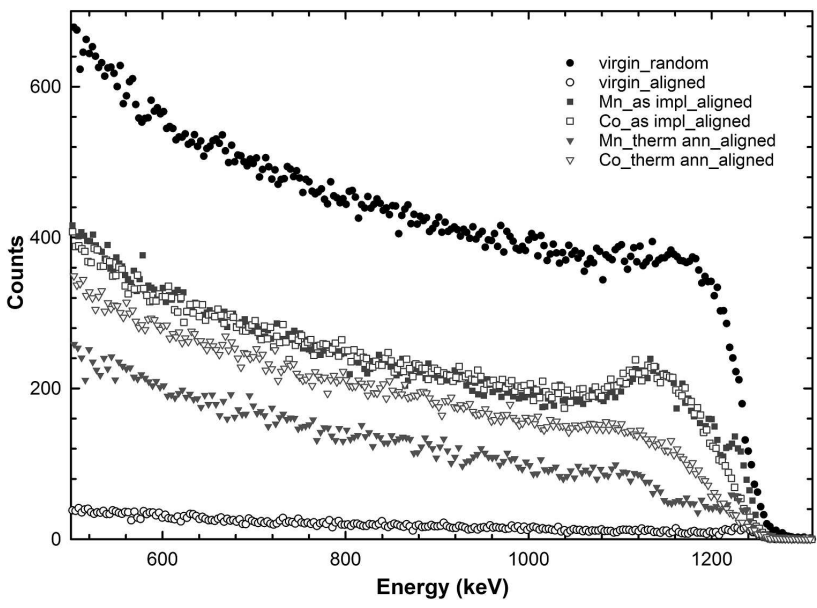

Fig. 4. The RBS random and aligned spectra obtained for $\mathrm{ZnO}$ single crystals before and after implantation with $120 \mathrm{keV}$ Co ions and $120 \mathrm{keV} \mathrm{Mn}$ ions to a fluence $1.2 \times 10^{16}$ ions $/ \mathrm{cm}^{2}$ and after thermal annealing at $800{ }^{\circ} \mathrm{C}$.

There was made a comparison of the post-implanted damage and recovery for $\mathrm{ZnO}$ after $120 \mathrm{keV}$ Co-ion and after $120 \mathrm{keV}$ Mn-ion bombardment. Figure 4 shows the random and (0001) aligned RBS spectra obtained for $\mathrm{ZnO}$ single crystals prior to and after ion bombardment with $120 \mathrm{keV} \mathrm{Co}$ and $120 \mathrm{keV}$ Mn ions to the same fluence of $1.2 \times 10^{16}$ ions $/ \mathrm{cm}^{2}$ and also after the thermal annealing process. As it can be seen, for both samples the post-implanted damage levels are the same, but the influence of thermal annealing process on the structure

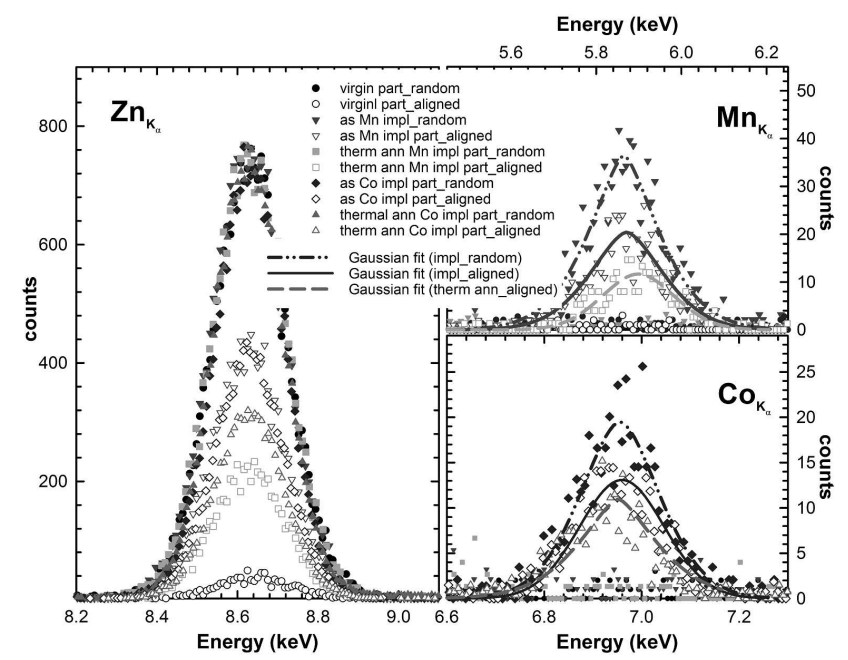

Fig. 5. The PIXE random and aligned spectra obtained for $\mathrm{ZnO}$ single crystals before and after implantation with $120 \mathrm{keV}$ Co ions and $120 \mathrm{keV} \mathrm{Mn} \mathrm{ions} \mathrm{to}$ a fluence $1.2 \times 10^{16} / \mathrm{cm}^{2}$ and after thermal annealing at $800{ }^{\circ} \mathrm{C}$. The lines show Gaussian approximations of the spectra.

recovery is much greater for the $\mathrm{Mn}$-doped $\mathrm{ZnO}$ sample. The cPIXE study on the TM lattice location for this sample was also carried out. The spectra reveal that Mn substitutions in the $\mathrm{ZnO}$ structure are much more effective than the Co ones, as shown in Fig. 5. These results are numerically presented in the Table.

The apparent chemical effects observed in our study between the $\mathrm{Mn}$ and $\mathrm{Co}$ implanted $\mathrm{ZnO}$ samples are usually attributed to different diffusion rates of both implanted elements. Faster diffusion of e.g. Mn atoms makes it easier for them to substitute $\mathrm{Zn}$ atoms and accelerate the annealing process. Diffusion of manganese and cobalt in $\mathrm{ZnO}$ was measured long time ago [18]. It follows from the derived diffusion parameters that Mn diffusion at $1070 \mathrm{~K}$ is slightly faster than the Co one. However, this conclusion should be treated with caution. The results recorded in Ref. [18] were obtained at a temperature of about $1400 \mathrm{~K}$ and need to be extrapolated to the present diffusion temperature. Moreover, the diffusion was measured in a perfect, undamaged crystal. We may expect quite different diffusion results when the crystal is damaged by ion implantation.

The diffusion lengths derived from the results of Ref. [18] reach 6 and $0.8 \mathrm{~nm}$ for $\mathrm{Mn}$ and Co, respectively, at the present diffusion temperature and duration. These values are far too low to account for ion implantation annealing which takes place in a region of a depth of about $100 \mathrm{~nm}$ (see Fig. 2).

Search through the literature reveals a reference in which $\mathrm{Co}$ diffusion in $\mathrm{ZnO}$ was measured after ion implantation [19]. According to these data, the diffusion length of $\mathrm{Co}$ in $\mathrm{ZnO}$ at the diffusion temperature and time amounts to $150 \mathrm{~nm}$. However, this reference does not show the results for manganese thus making comparison impossible. 
Therefore one can only speculate that considering thermodynamical reactions between the diffusing $\mathrm{Mn}$ or $\mathrm{Co}$ atom $\left(\mathrm{Mn}_{i}, \mathrm{Co}_{i}\right)$ and the substitutional $\mathrm{Zn}$ atom $\left(\mathrm{Zn}_{s}\right)$, the activation energy for $\mathrm{Mn}_{i}+\mathrm{Zn}_{s} \rightarrow \mathrm{Mn}_{s}+\mathrm{Zn}_{i}$ reaction is lower with respect to the respective reaction with $\mathrm{Co}_{i}$, thus leading to faster substitutionality of Mn atoms in $\mathrm{ZnO}$. This interpretation would obviously need experimental verification.

\section{Summary}

The global cRBS studies supported by the cPIXE measurements on the $\mathrm{ZnO}$ (0001) single crystals and GaN (0001) epitaxial layers implanted with $\mathrm{Co}$ and $\mathrm{Mn}$ ions were carried out.

Our study show incomplete amorphisation of both structures after ion implantation, and partial recovery structure after thermal annealing at $800^{\circ} \mathrm{C}$ for $\mathrm{ZnO}$ only. It was also observed that Co-implanted atoms are partially built into the $\mathrm{ZnO}$ structure after implantation and that effect improves after thermal annealing. In turn, the GaN post-implantation damage after thermal annealing remains unchanged, and also no Co-substitution into GaN was observed.

The cRBS and cPIXE studies for $\mathrm{ZnO}$ implanted with Co and Mn ions show the same post-implantation damage in both cases, but after thermal annealing much better recovery and much more substitutive effect for Mndoped in $\mathrm{ZnO}$ samples were observed.

Many $\mathrm{ZnO}$ features are similar to $\mathrm{GaN}$, but the $\mathrm{GaN}$ production is much more difficult and expensive than that of $\mathrm{ZnO}$, so $\mathrm{ZnO}$ is a very attractive material for several new applications and a good alternative to GaN. Much better results were obtained for $\mathrm{ZnO}$ than $\mathrm{GaN}$.

\section{Acknowledgments}

We are grateful to Professor A. Turos for valuable discussion and comments. Technical assistance of Andrzej Zagórski is gratefully acknowledged.

This work was supported by the European Community as an Integrating Activity "Support of Public and Industrial Research Using Ion Beam Technology (SPIRIT)" under EC contract no. 227012 - project TNA 207. The project was awarded a financial support of the Polish Ministry of Science and Higher Education from the Science Fund for 2013-2014 fiscal years for execution of the co-financed international project (Grant No. 2786/SPIRIT/2013/0).

\section{References}

[1] J.K. Furdyna, J. Appl. Phys. 64, R29 (1988).

[2] S.J. Pearton, D.P. Norton, M.P. Ivill, A.F. Hebard, J.M. Zavada, W.M. Chen, I.A. Buyanova, J. Electron. Mater. 36, 462 (2007).

[3] I. Zutić, J. Fabian, S. Das Sarma, Rev. Mod. Phys. 76, 323 (2004).

[4] T. Dietl, H. Ohno, F. Matsukura, J. Cibert, D. Ferrand, Science 287, 1019 (2000).

[5] K. Sato, H. Katayama-Yoshida, Semicond. Sci. Technol. 17, 367 (2002).

[6] R.P. Borges, J.V. Pinto, R.C. da Silva, A.P. Goncalves, M.M. Cruz, M. Godinho, J. Magn. Magn. Mater. 316, e191 (2007).

[7] S. Zhou, K. Potzger, J. von Borany, R. Grötzschel, W. Skorupa, M. Helm, J. Fassbender, Phys. Rev. B 77, 035209 (2008).

[8] K. Potzger, S. Zhou, Phys. Status Solidi B 246, 1147 (2009).

[9] S. Zhou, K. Potzger, Q. Xu, G. Talut, M. Lorenz, W. Skorupa, M. Helm, J. Fassbender, M. Grundmann, H. Schmidt, Vacuum 83, S13 (2009).

[10] A. Audren, A. Hallén, M.K. Linnarsson, G. Possnert, Nucl. Instrum. Methods Phys. Res. B 268, 1842 (2010).

[11] W.K. Chu, Phys. Rev. 13, 2057 (1976).

[12] M. Mayer, in: Workshop on Nuclear Data for Science and Technology: Materials Analysis Trieste, Trieste 2003, p. 55.

[13] T.B. Johansson, K.R. Axelsson, S.A.E. Johansson, Nucl. Instrum. Methods Phys. Res. B 84, 141 (1970).

[14] L. Nowicki, A. Turos, R. Ratajczak, A. Stonert, F. Garrido, Nucl. Instrum. Methods Phys. Res. B 240, 277 (2005).

[15] A. Turos, P. Jóźwik, L. Nowicki, N. Sathish, Nucl. Instrum. Methods Phys. Res. B 332, 50 (2014).

[16] A. Stonert, K. Pągowska, R. Ratajczak, P. Caban, W. Strupinski, A. Turos, Nucl. Instrum. Methods Phys. Res. B 266, 1224 (2008).

[17] Z. Werner, R. Ratajczak, J. Gosk, M. Barlak, A. Twardowski, C. Pochrybniak, Q. Zhao, Appl. Surf. Sci. 310, 242 (2014).

[18] F.W. Kleinlein, R. Helbig, Z. Phys. 266, 201 (1974).

[19] O. Koskelo, J. Raisanen, F. Tuomisto, D. Eversheim, K. Grasza, A. Mycielski, Thin Solid Films 518, 3894 (2010). 